\title{
Fuzzy based sensorless tracking controller on the dual-axis PV panel for optimizing the power production
}

\author{
Bandiyah Sri Aprillia ${ }^{1 *}$, Muhammad Zakiyullah Romdlony ${ }^{2}$, Jangkung Raharjo ${ }^{3}$, Yogi Ghifari Sidik ${ }^{4}$ \\ ${ }_{1,2,3,4}$ School of Electrical Engineering, Telkom University \\ ${ }_{1,2,3,4} \mathrm{Jl}$. Terusan Buah Batu Dayeuhkolot Bandung, 40257, Indonesia \\ *Corresponding email: bandiyah@telkomuniversity.ac.id
}

Received 28 October 2021, Revised 21 November 2021, Accepted 7 December 2021

\begin{abstract}
In general active sun trackers move because they respond to light sensors that measure the intensity of sunlight. However, sensor-based trackers are usually more expensive than sensor-less trackers. In addition, based on several studies, a comparison between the sensor and sensorless based tracker only reports lower tracking error and higher power generation for sensor-based than sensorless tracker. However, it does not include an analysis of energy use on the sensor. Therefore, this study aims to design a sensorless closed-loop tracking system for solar panels with two degrees of freedom. The tracking controller in this study is based on the Fuzzy Logic Controller (FLC) method. In this study, a dual-axis PV can increase power output by $20.2 \%$ compared to a fixed PV $\left(0^{\circ}\right.$ axis position). In comparison to a fixed PV, dual-axis PV adjusts the solar panel perpendicular to the sun's position to optimize electrical conversion.
\end{abstract}

Keywords - Altitude Angle, Azimuth Angle, Fuzzy Logic Controller, Sensorless Tracker.

Copyright (C) 2021 JURNAL INFOTEL

All rights reserved.

\section{INTRODUCTION}

Indonesia has an average irradiance distribution of $4 \mathrm{kWh} / \mathrm{m}^{2} /$ day for each area [1]. Therefore, solar energy harvesting technology has been largely implemented in Indonesia. Solar power harvesting can be installed on-grid or off-grid [2-3]. The solar module is paired to the battery as a storage medium and connected to an inverter to meet load requirements [2]. On the contrary, Solar panels linked to the State Electricity Enterprise (PLN) network are classified as on-grid solar power systems [3-4].

The amount of electrical energy converted by a solar power system is commonly determined by the intensity of solar radiation [2-3]. However, radiation intensity changes daily due to the earth's movement. By maintaining the solar panel's (SP) angle from the light source upright at all times, a controller capable of tracking the sun's position (sun tracker) can be utilized to optimize the quantity of energy that solar panelssolar panels can collect. A sun tracker can improve the quantity of energy converted by up to $60 \%$ [5-8]. Some publications use both specialized algorithms with different sensor types to track the sun's position.

Single and dual axis are established as the main two types of sun tracker technologies. In a dual-axis system, the controlled angle is the azimuth angle and the altitude angle. Whereas in single-axis systems, only one of the two angles can be controlled [9-10].

The implementation of open-loop control on a PLCbased dual-axis solar tracker system in Jordan was able to increase the solar radiation received by PV as much as $41.34 \%$ [11]. Furthermore, the implementation of PLC-based dual-axis open loop solar tracker control was capable of producing $147.9 \mathrm{Wh}$ of Power, with the actuator and controller requiring $5.89 \%$ of the increased PV power [12]. Based on observations [12] a fixed PV produces $61.49 \mathrm{Wh}$ power whilst a tracking PV produces $147.9 \mathrm{Wh}$. The implementation of type-1 fuzzy control method, with voltage error and voltage error change as system input and the changes of DC motor speed as system output using PWM would be capable of producing a reliable system. The deviation/error of each input is in line with the consensus of a fuzzy design [13].

In general, active sun trackers move because they respond to light sensors that measure the intensity of sunlight. However, sensor-based trackers are more expensive than sensorless trackers. In addition, based on several studies, a comparison between sensor and 
sensorless based trackers [14-15] only reports lower tracking error and higher power generation for sensorbased than sensorless tracker. However, it does not include an analysis of energy use on the sensor. Therefore, this study aims to design a sensorless closedloop tracking system for solar panels with two degrees of freedom. The FLC approach is used to create the tracking controller in this study. Where the system is designed to regulate the position of the SP in such a way that it is expected to always be perpendicular to the position of the sun throughout the day to produce optimal amounts of electricity from the SP in Telkom University (6 $\left.58^{\prime} 26 \mathrm{~S} 107^{\circ} 37^{\prime} 49 \mathrm{E}\right)$, Indonesia.

\section{RESEARCH METHODS}

\section{A. Azimuth and tilt Angle Determination}

Azimuth direction and tilt angle for photovoltaic panels require the geographical position of an area for optimization [16]. This means that each region's azimuth direction and tilt angle parameters are unique. For example, Telkom University in Bandung Regency coordinates $6^{\circ} 58^{\prime} 26 \mathrm{~S} 107^{\circ} 37^{\prime} 49 \mathrm{E}$. This place is used as a field for photovoltaic research. No one has conducted research on the optimal setting of azimuth and tilt angle from previous research.

This paper discusses optimizing the azimuth direction and tilt angle of photovoltaic panels in the Telkom University district, Bandung, West Java, which aims to optimize the absorption of solar radiation by photovoltaic panels. First, solar radiation falling on an inclined surface is used to find the maximum tilt angle [17-19]. In general, the sum of direct, diffused and reflected radiation, or albedo is used to calculate the total average radiation on the inclined plane's surface.

The calculation of the total radiation that falls on an inclined plane is one of its components: calculating direct radiation. Direct radiation on an inclined surface can be shown by (1) [17-19]:

$$
\mathrm{HB}=(\mathrm{Hg}-\mathrm{Hd}) \mathrm{Rb}
$$

where $\mathrm{Hg}$ and $\mathrm{Hd}$ are global radiation and diffusion radiation in the horizontal plane. Whereas $\mathrm{Rb}$ is the ratio of direct radiation on an inclined plane to the horizontal plane. Rb can be calculated by (2) [17-19]:

$$
R_{b}=\frac{\cos \theta}{\cos \theta_{z}}
$$

where $\theta$ is angle of incidence, which is calculated based on (3) [17-19]:

$$
\begin{aligned}
\cos \theta= & \cos \beta \sin \varphi \sin \delta-\sin \beta \cos \varphi \sin \delta \cos \gamma+ \\
& \cos \beta \cos \varphi \cos \delta \cos \omega+ \\
& \sin \gamma \delta \sin \beta \cos \delta \sin \omega+ \\
& \cos \delta \sin \varphi \sin \beta \cos \gamma \cos \omega
\end{aligned}
$$

The zenith angle $\left(\theta_{-} z\right)$ is the angle formed by the normal plane's vertical line converging the line of incoming sunlight. The zenith angle can be obtained using (4) [17-19].

$\cos \theta_{z}=\cos ^{-1}(\cos \emptyset \cos \delta \cos \omega+\sin \emptyset \sin \delta)$

In equation (3), $\varphi$ is the latitude position, $\beta$ is tilt angle, $\gamma$ is azimuth direction in the southern hemisphere by 0 $\circ$ facing south and $180^{\circ}$ facing north [17-18], $\omega$ is sundial angle, $\delta$ is declination angle. Declination angle can be found using (5) [17-19]:

$$
\delta=23.45 \sin \left(\frac{360}{365}[284+n]\right)
$$

With $n$ representing the number of days in a month [1719].

A circle is formed through the north and south poles on the celestial sphere centered on the Earth's axis. This circle is called the time circle and forms a $90^{\circ}$ angle to the celestial equator. Each circle of time forms an angle to the circle of meridians which is called the angle of time. In the time angle coordinate system, determining the celestial body requires the clock angle of the star $(\mathrm{t})$ and the star's declination $(\delta)[19]$.

If a star is on the meridian, the time circle coincides with the meridian, but the time circle with the meridian will form an angle if the star is not on the meridian. Therefore, the time angle is formed by the celestial meridian circle with the time circle [19].

The calculation of the time angle starts from the upper meridian. It ends at the lower meridian so that the time angle is divided into two parts, namely the western part of the sky $(+)$ and the eastern part of the sky (-) where the amount of time angle is from $0^{\circ}$ to $180^{\circ}$ [17-19].

Every hour the time angle changes by $\pm 15^{\circ}$. This is caused by the daily motion of celestial bodies caused by the Earth's rotation. Thus, the number of degrees of time angle can be transferred into hours, minutes, and seconds. The time angle is formulated as follows [1719].

$$
\omega=(t-12) \times \frac{360}{24}
$$

With $\mathrm{t}$ stating the time in a day.

Azimuth is generally measured from south to west to the projection of a star on the horizon. But there is also azimuth which is measured from north to east. The deviation to the east is negative and to the west is positive. The azimuth angle (s) can generally be calculated using (7) [17-19]:

$$
\gamma_{s}=\operatorname{sign}(\omega)\left|\cos ^{-1}\left(\frac{\cos \theta_{z} \sin \emptyset-\sin \delta}{\sin \theta_{z} \cos \emptyset}\right)\right|
$$

Slope can be obtained using (8) [17-19].

$$
\beta=\tan ^{-1}\left(\tan \theta_{z} x \cos \gamma_{s}\right)
$$


The tilt angle of PV is the angle between the surface in question and the horizontal surface [17-19].

\section{B. Fuzzy Inference System}

Equations 7 and 8 are the azimuth and tilt angle equations of PV; both equations are nonlinear because there are cosine and sine functions. Therefore, FLC is implemented into the PV drive system. One of the processes in using FLC is the Fuzzy inference system, which draws conclusions from several fuzzy rules. Input and output in Fuzzy Inference System (FIS) is a crisp value. The processes in FIS are Fuzzification, Fuzzy Rules, and Defuzzification.

Fuzzification is a method of transforming a crisp input (linguistic variables) into a fuzzy set with each membership function [20-23].

Fuzzy Rules consist of rules based on fuzzy logic to express a condition. The formulation of rules greatly affects the precision of the model; at the decisionmaking stage, it is determined based on the design of the rules. If-then rules are associated with logical AND and OR operations [20-23].

Defuzzification is the technique of restoring crisp values to fuzzy values that are presented as fuzzy output sets with a membership function. This is necessary because a crisp value is needed in real applications [20-23].

Research on the application of control algorithms continues to be developed both in simulation and in real plants. FLC are commonly built using a type-1 fuzzy set called a type-1 FLC [20]. Type-1 FLC has been applied mainly for controlling nonlinear systems [21]. However, research shows that type-1 FLC has weaknesses in the uncertainties of membership function modeling [22]. Type-2 FLC, also known as Type-2 Interval FLC, could further handle model type1 fuzzy sets with uncertainty membership functions [23]. Therefore, this study would use the implementation of type-2 FLC in real plants to control the yaw and pitch angle of the SP against the azimuth and solar elevation angle.

\section{System Design}

The system consists of a series of drive mechatronics systems consisting of a linear motor with a motor driver and a 2-axis motion axis to direct the 340wp type solar panel towards the sun. Fig.1 explains the position control system divided into several sections, namely: the input section, the controller section, and the plant section.

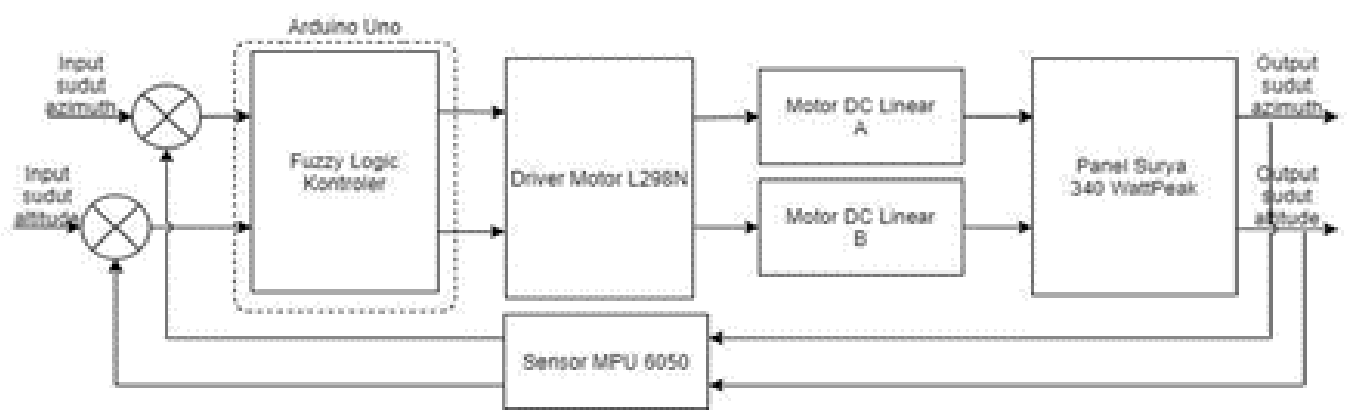

Fig. 1. Block diagram.

In the input section, there is a process of assigning input values carried out by the user, i.e., the azimuth setpoint value in degrees obtained using (7) and the tilt angle in degrees are obtained using (8).

Then the controller functions to process the error signal generated from the comparison of input values and the value of the sensor using the FL control method.

A controller controls the plant section in the form of an object controls the plant section in the form of an object, the plant in this system is the position of the solar tracker angle based on the azimuth and altitude angle. If the desired angle position has not been reached, the controller would improve the system response. The position of the angle will then be read by the MPU6050 sensor then compared to the angle that has been previously set. This process will loop until the output value reaches the setpoint value. Furthermore, Fig. 1 is described in detail in section III. The hardware diagram is shown in Fig.2, which is the design of a solar panel drive system circuit.

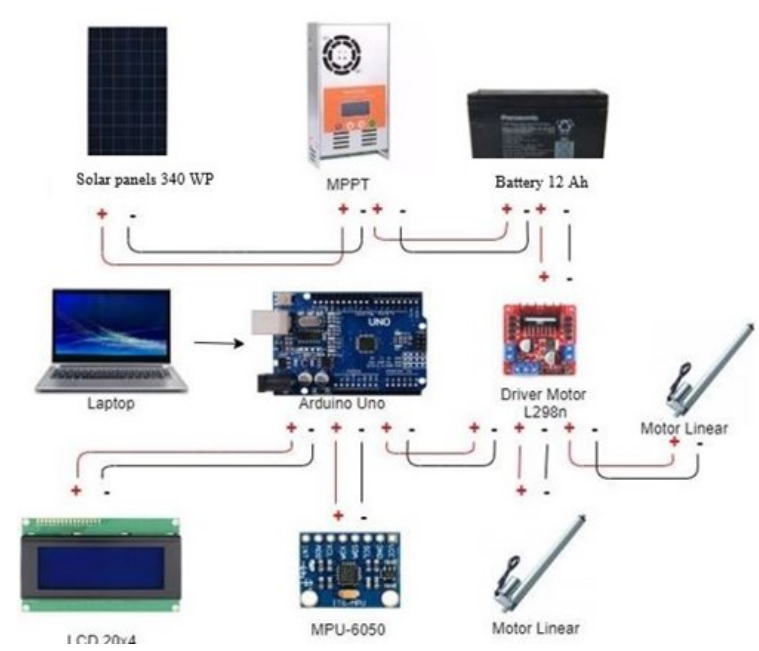

Fig. 2. System design 
The solar cell functions as a medium that the actuator will control to change its position. MPPT functions as a voltage or current regulator, which can keep the battery from overcharging. The batteries used in this study were 3 types of VRLA with a capacity of $12 \mathrm{Ah}$. Linear DC motor functions as an actuator and moves solar cells in the direction specified on the controller. In the meantime, the motor driver L298n controls the direction and speed of the DC motor's movement in the PWM value. The sensor used is the MPU 6050 sensor. In this sensor, there is an accelerometer and a gyroscope used to measure the tilt of the angle displayed on the LCD.

The mechanical design of the system is in the form of a frame design for a dual-axis solar panel drive system. In this study, the mechanical framework of the system uses galvalume iron to make it light and strong. The design of the mechanical system framework is divided into several parts; these parts are represented by the numbers shown in Fig. 3 and Fig. 4 .

Figure 3 is the mechanical design of the system. In part 1 there is solar panel support measuring $200 \mathrm{~cm} \mathrm{x}$ $100 \mathrm{~cm} \times 5 \mathrm{~cm}$ then in part 2 there is a box to store the Solar Charger Controller then in part 3 is a support pole from a mechanic measuring $3 \mathrm{~cm} \times 5 \mathrm{~cm} \times 160 \mathrm{~cm}$ and in the 4th part is a support from the entire mechanical system that supports the load with dimensions of 100 $\mathrm{cm} \times 100 \mathrm{~cm} \times 5 \mathrm{~cm}$.

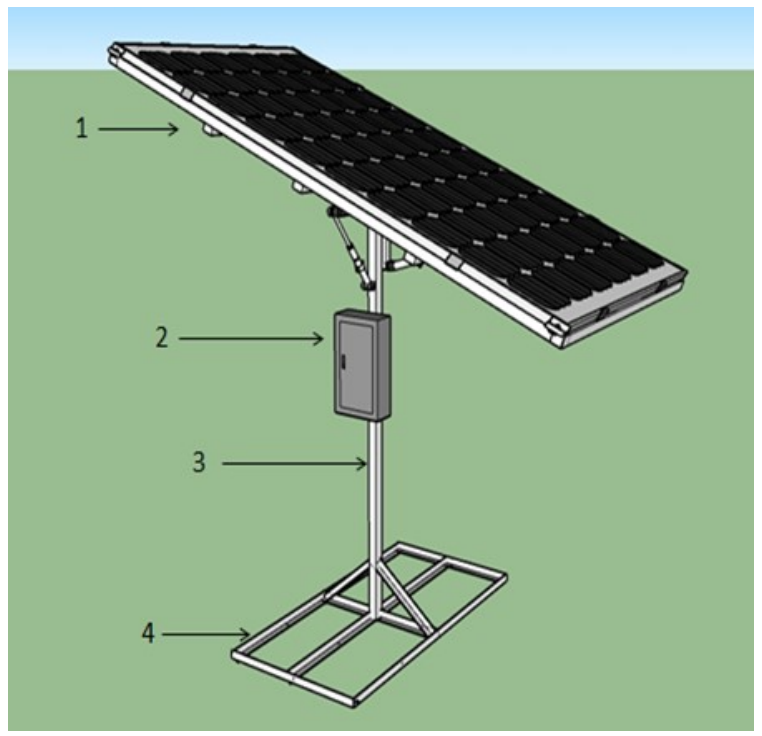

Fig.3. Solar tracker mechanics.

Figure 4 is the axis of rotation of a dual-axis mechanic. It can be seen in section 5 there is a box with dimensions $6 \mathrm{~cm} \times 12 \mathrm{~cm} \times 18 \mathrm{~cm}$, which contains a microcontroller, motor driver, sensor, and LCD then in section 6 , there is a linear DC motor that has been installed on a machine that can move south or north, and in section 7 there is a linear DC motor that has been attached to a mechanic that can move from an eastwest direction.

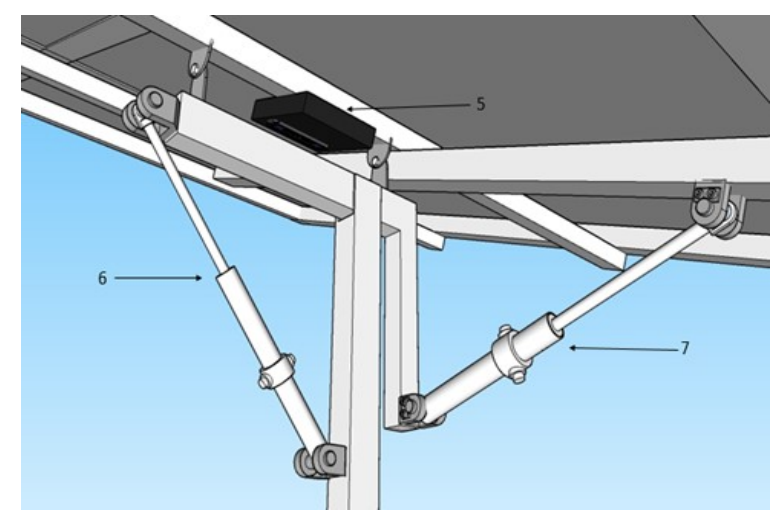

Fig. 4. Dual-axis mechanic.

\section{Fuzzy Logic Controller}

In designing FL, several processes must be carried out. By the system block design, FL is used to process the angle sensor readings of the roll and pitch with dc motor speed as an output. The system consists of error and delta error from the angle sensor serve as system input, while de motor speed serves as system output.

It is necessary to carry out the two steps: formation of membership functions and application of implication functions to execute the FL process,

A membership function (MF) is produced in this stage for each input and output, resulting in three membership sets. Namely for Error, MF, and DC motor. For the membership set for every input and output can be seen in Fig. 5 - Fig. 7 .

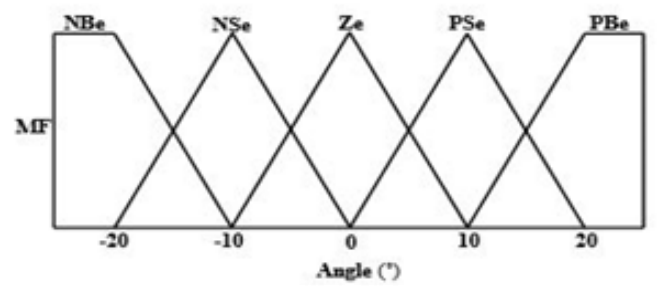

Fig. 5. Error $\left(^{\circ}\right) \mathrm{MF}$

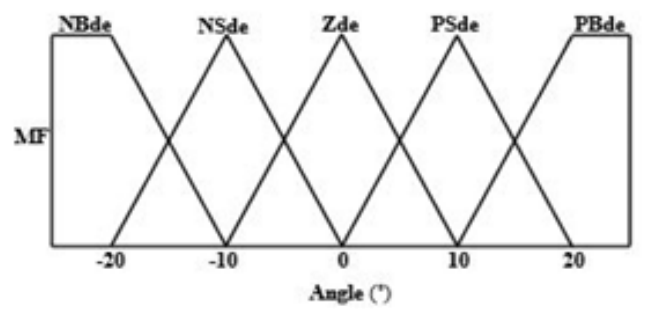

Fig. 6. Delta Error $\left({ }^{\circ}\right) \mathrm{MF}$.

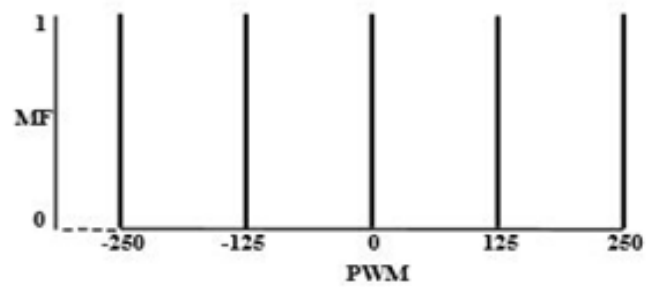

Fig. 7. DC Motor MF. 
In this stage, a fuzzy rule will be made between system input and output. The relationship between input and output is shown in Table 1, namely the Fuzzy rules, made in tabular form. For fuzzy rules the system can be illustrated with the Table 1 .

Tabel 1. Fuzzy rules table

\begin{tabular}{llcccc}
\hline \multirow{2}{*}{$\begin{array}{c}\text { Delta } \\
\text { error }\end{array}$} & \multicolumn{5}{c}{ Error } \\
\cline { 2 - 6 } & Nbe & Nse & Ze & Pse & Pbe \\
\hline NBde & ONB & ONB & ONB & OPS & OPB \\
NSde & ONB & ONB & ONS & OPS & OPB \\
Zde & ONB & ONB & OZ & OPB & OPB \\
PSde & ONB & ONS & OPS & OPB & OPB \\
PBde & ONB & ONS & OPB & OPB & OPB \\
\hline
\end{tabular}

At rule composition stage, the process of using the basic Zadeh operators for fuzzy sets are: AND, OR, and NOT operators.

The affirmation process for system output is carried out at the affirmation stage so that certain crisp values can be taken as output. The defuzzification process is carried out in the Takagi-Sugeno method by finding a weighted average. The equation for weight average is as follows (9).

$$
\text { Weight average }=\left(\left(\sum \mu \boldsymbol{i} . \boldsymbol{z}\right)\right) /\left(\sum \boldsymbol{\mu} \boldsymbol{i}\right)
$$

Where $\boldsymbol{\mu} \boldsymbol{i}$ as the MF and $\boldsymbol{z}$ as the system output constant.

\section{E. Fuzzy Control Design}

The flowchart of the system is as shown in Fig.8. The position control system starts from determining the setpoints and variables needed in this system, and the MPU6050 sensor will then read the error at an angle. If there is a difference in angle, the system will correct it using the FL control method. The motor will then move the solar panel to the specified angle position. This process will be repeated to achieve and maintain the desired input values.

\section{RESULTS}

The angle value in the system is measured using the MPU 6050 sensor. Tests are carried out to find out whether the MPU 6050 value is in accordance with the specified value and function. If the sensor is ready, the value read by the sensor is in the form of an angle. This test is carried out to find out that the device is working according to its function. The sensor value obtained will be compared with the arc value.

Figure 9 and 10 are graphs of comparing the arc and the MPU-6050 sensor. The MPU6050 sensor has an error of pitch $=0.53$ and roll $=0.68$. Therefore, the MPU 6050 sensor is suitable for this system and has a high accuracy value.

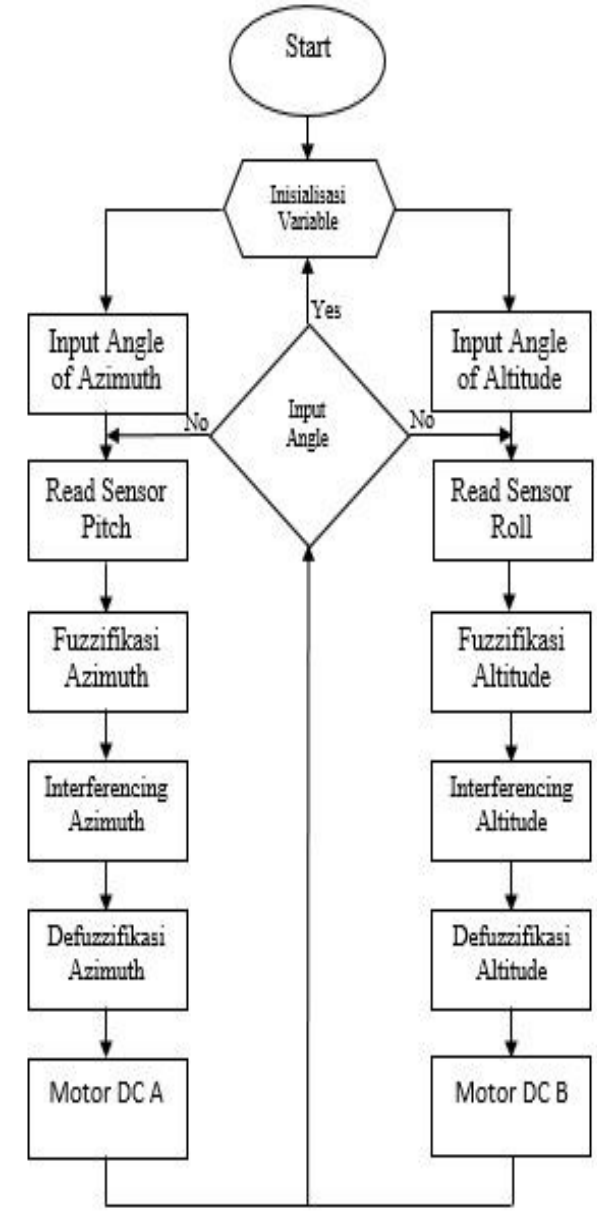

Fig. 8. Fuzzy control design

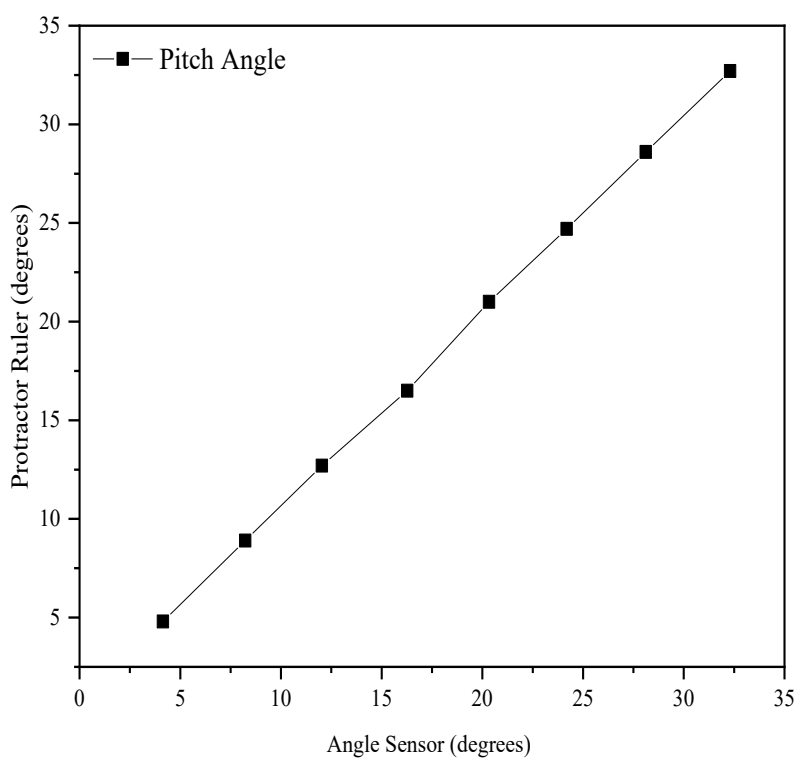

Fig. 9. Graph showing arc comparison with MPU 6050 sensor at pitch angle. 


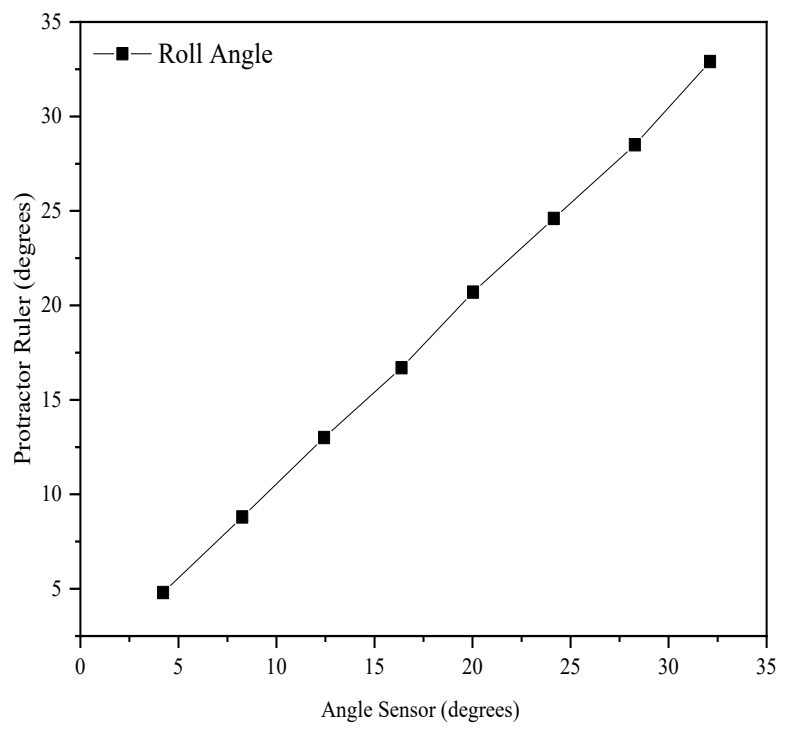

Fig.10. Graph showing arc comparison with MPU 6050 sensor at angle roll.

Motor driver testing aims to determine the voltage issued by the motor driver at a predetermined PWM value. First, motor driver testing is done by connecting the motor driver to the $12 \mathrm{~V}$ battery. Afterward, set the value 0 on the Arduino PWM, then measure the motor driver output using a digital multimeter to find out the resulting voltage. Next, repeat the measurement with a different PWM value from 0 - 255 as specified.

Figure 11 graph showing comparison of PWM value with voltage output for driver motor based on Fig.11, it can be concluded that the greater the PWM value is given, the greater the voltage output. There is a minimum PWM to move on motor an of 50 PWM 255 PWM and on motor $b$ of 40 PWM - 255 PWM.

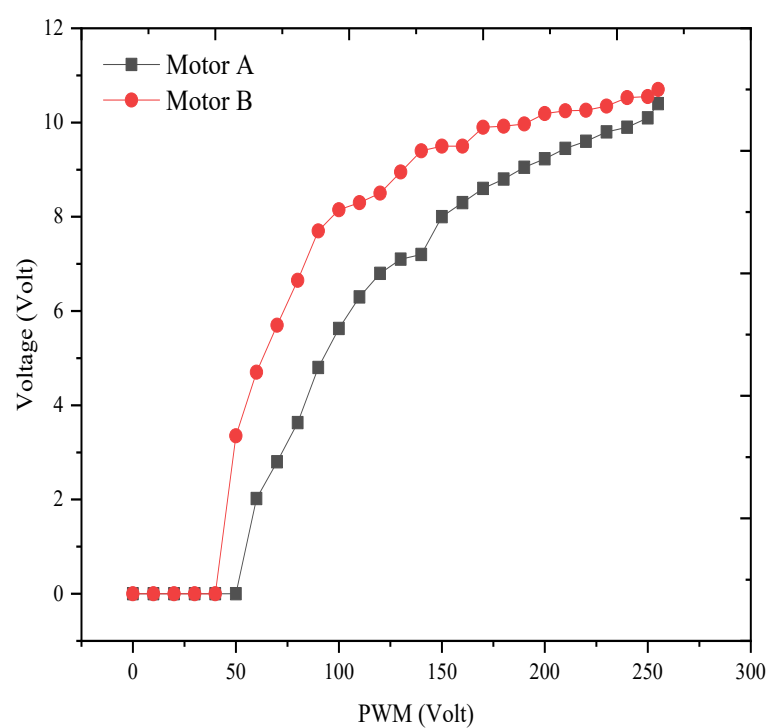

Fig. 11. Graph showing comparison of PWM value with voltage output for driver motor.

The relationship between the hour angle and the hour can be determined using (6). Then the hour angle will be negative before midnight and the hour angle will be positive after midnight, as shown in Fig. 12.

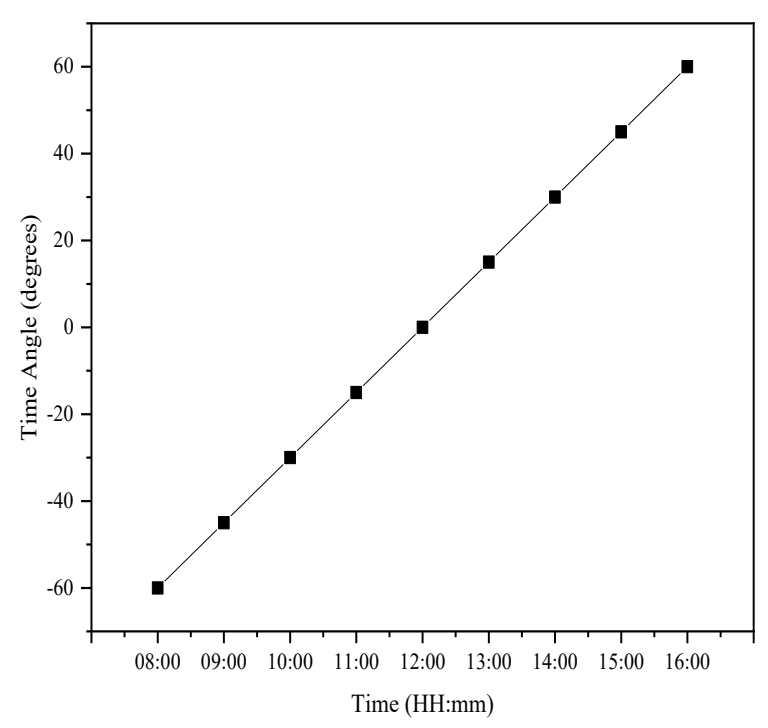

Fig.12. Hourly angle versus time.

The calculation of the hour angle is indispensable in testing the solar module in a horizontal position or position following the movement of the sun's direction. The relationship between the sundial angle and the deviation from the direction of the sun is determined using equations 6 and 7. $\gamma \mathrm{s}$ is the angle of deviation from the direction of the sun from south to west, then $\gamma \mathrm{s}$ is negative before 12 o'clock and positive after 12 o'clock as shown in Fig. 13.

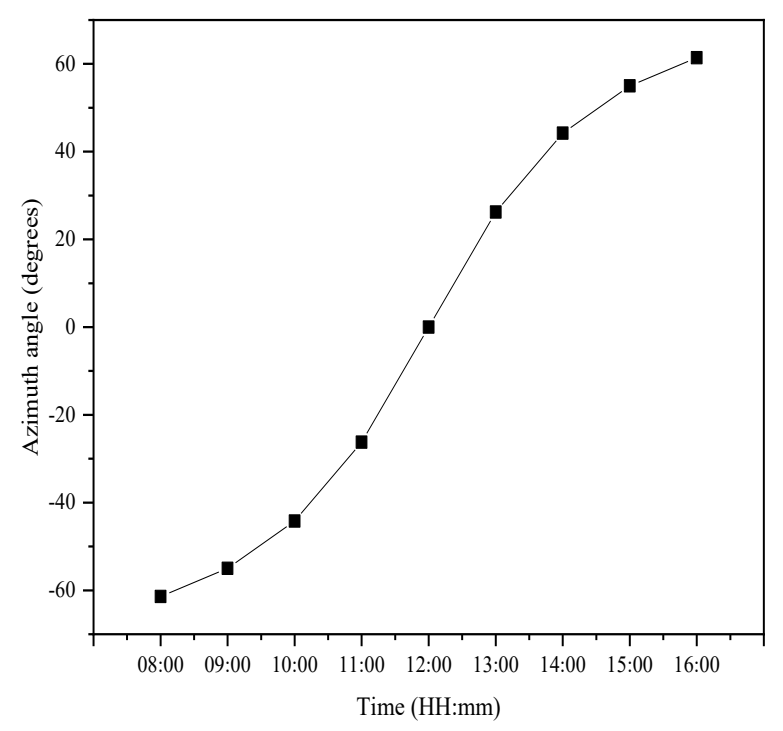

Fig. 13. The relation of angle of deviation of the direction of the sun's movement against time.

To obtain the maximum value of irradiation, short circuit current and open circuit voltage, the tilt angle of the solar module is needed from the change in horizontal position to the movement of the sun's direction. The tilt angle of the solar module can be obtained from equation 8 , so the relationship between 
the clock and the slope of the solar module can be obtained as shown in Fig. 14.

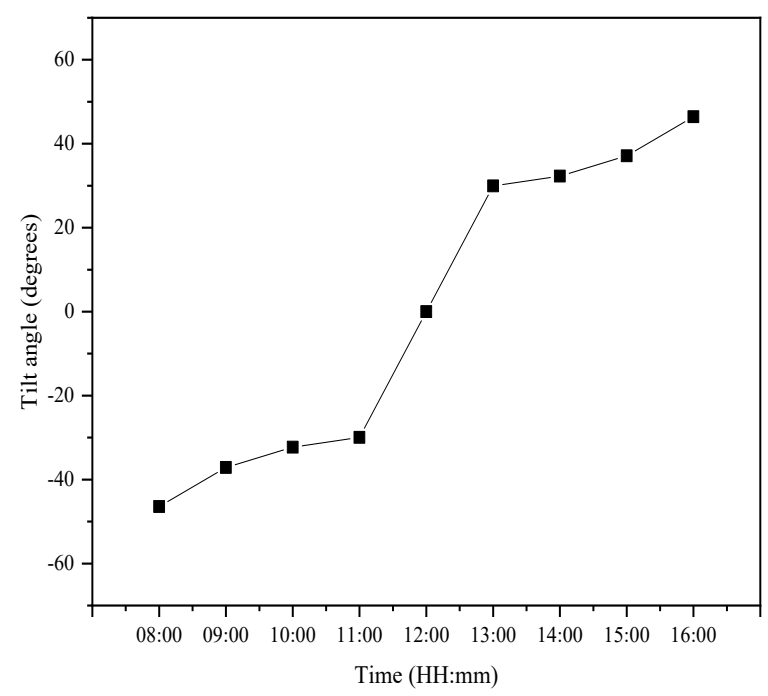

Fig.14. The angle of solar module tilt against time.

Figures 15 and 16 show the results of testing the angle of the dual-axis system with a fuzzy-based controller at a set point of $10^{\circ}$ and $20^{\circ}$ respectively for pitch angle and roll angle.

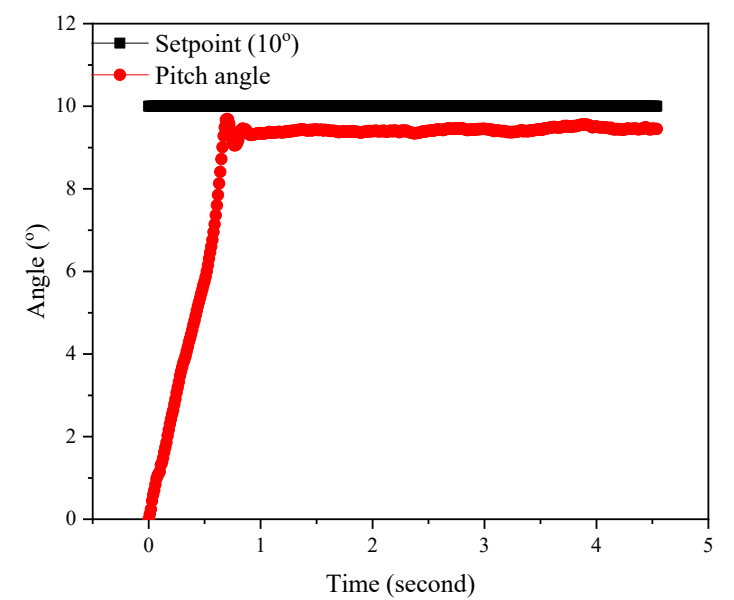

Fig.15. Sensor reading graph with pitch angle at setpoint of $10^{\circ}$

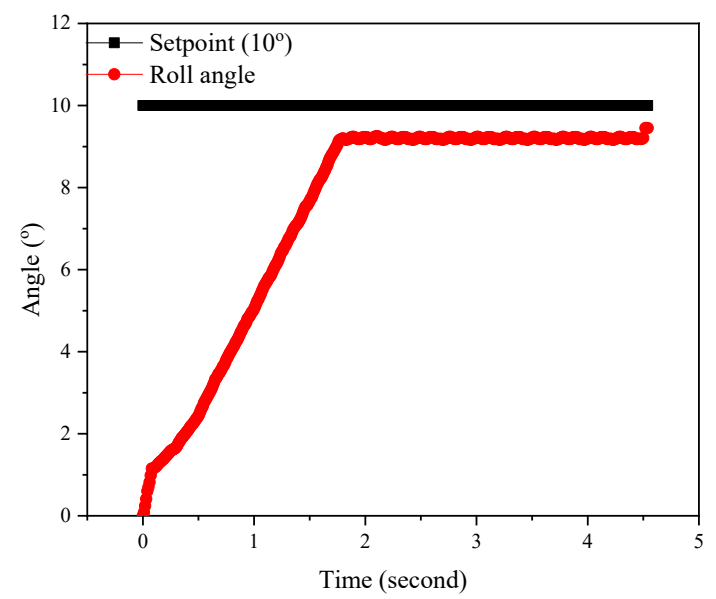

Fig.16. Sensor reading graph with roll angle at a set point of $10^{\circ}$
Sensor readings at the pitch angle set point in Fig. 15, obtained a rise time value of 0.33 seconds, a settling time of 0.72 seconds, and error of $0.6^{\circ}$.

Sensor readings at the roll angle set point in Fig.16 obtained a rise time value of 0.82 seconds, a settling time of 1.82 seconds and an Error of $10.77^{\circ}$.

Based on the system response graph in Fig.17 for testing, the pitch angle obtained with a set point of 20 ${ }^{\circ}$ obtained a rise time value of 0.93 seconds, a settling time of 1.78 seconds, and an error of $1.05^{\circ}$.

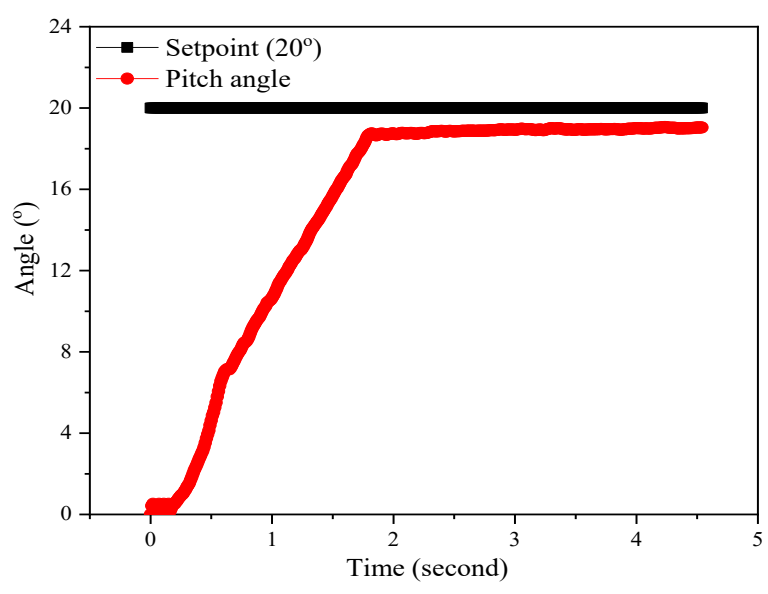

Fig.17. Sensor reading graph with pitch angle at set point of $20^{\circ}$

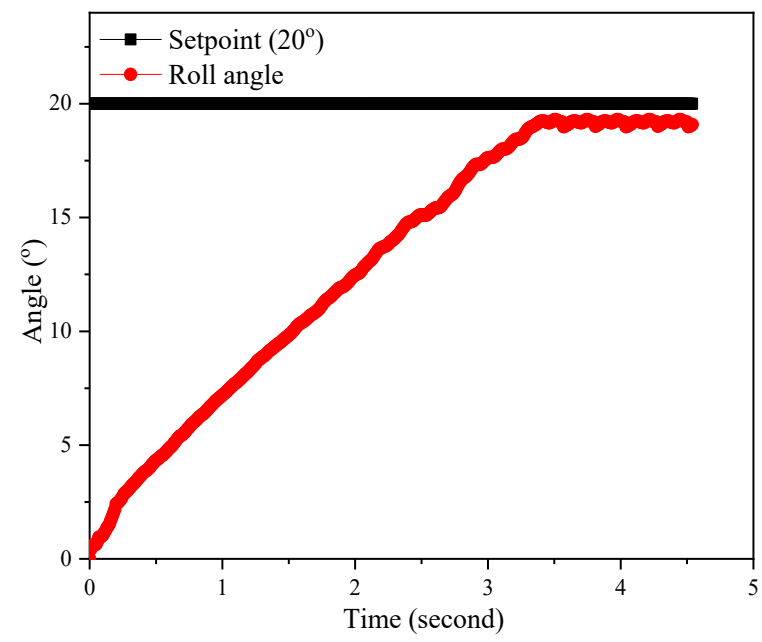

Fig.18. Sensor reading graph with roll angle at set point of $20^{\circ}$

Graph of system response with FL range in Fig.18 shows the value of rising time of 1.55 seconds, settling time of 3.36 seconds, and error of $0.74^{\circ}$.

Solar cell testing is done by measuring the output produced by solar cells using a digital multimeter. The test is carried out from 08.00 WIB to 16.00 WIB. A sampling of test data is taken every 15 minutes; this is intended to obtain a tight sampling of data. The test was carried out on January 5, 2020. 


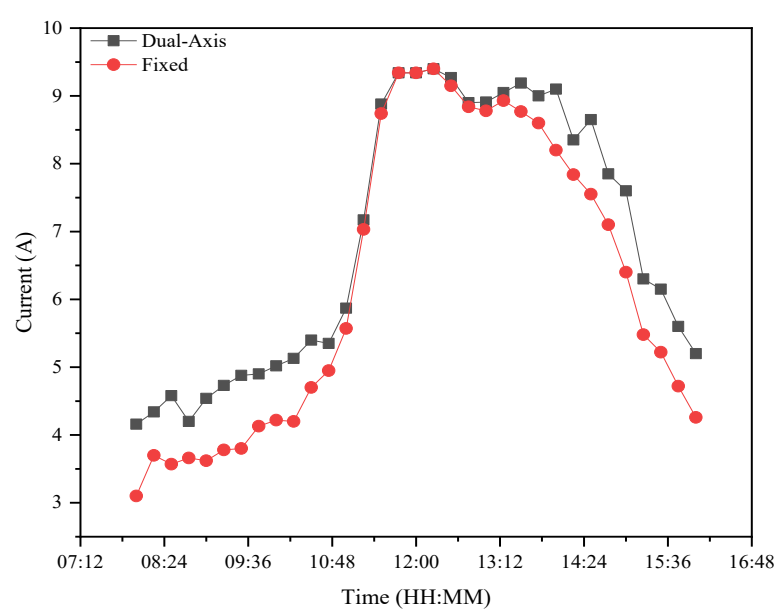

Fig.19. Comparison of short circuit current to time.

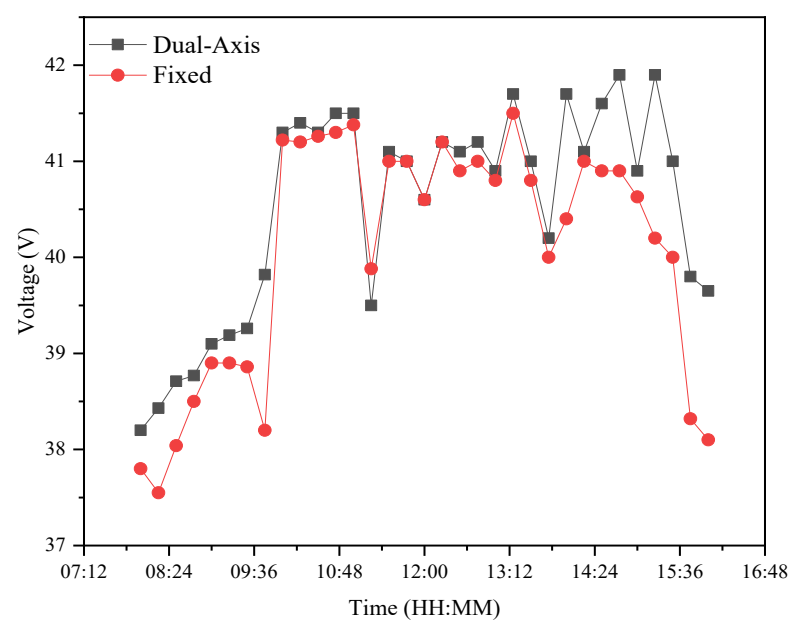

Fig.20. Comparison of open circuit voltage to time.

Output power is generated by multiplying the fill factor (FF) on the solar module with the open circuit voltage (Voc) and short circuit current (Isc) obtained at the time of testing, so that a graph of the output power in the position follows the direction of the sun and the solar module at the time.

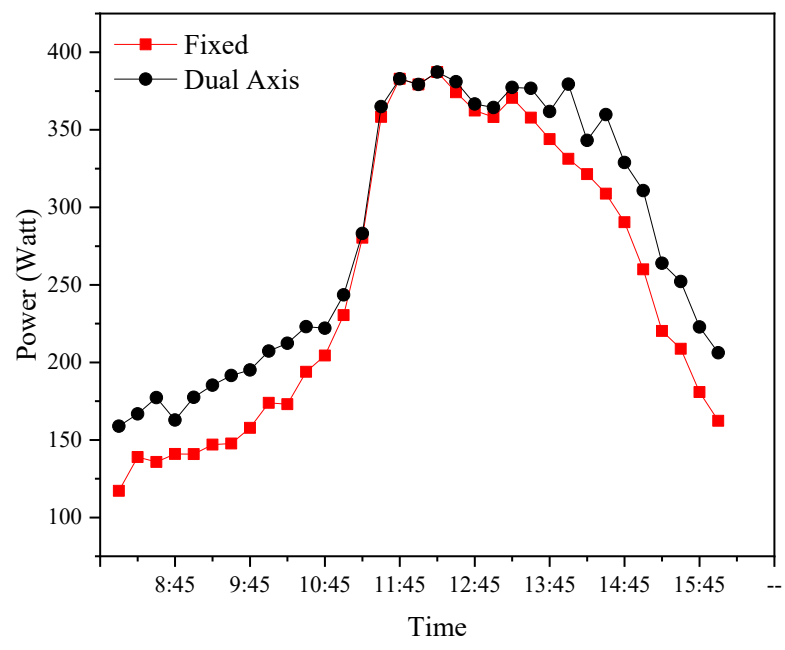

Fig. 21. Comparison of fixed PV and dual axis PV power output.
As illustrated in Fig.21, the output power measurement is used to estimate the ability of solar cells to convert solar radiation into electrical energy for each time shift.

\section{DISCUSSION}

PV testing is done by measuring the output produced by a dual-axis panel system using a digital multimeter and then comparing it with the output of a fixed panel system. The azimuth angle input on the dual-axis panel system is obtained from the sundial angle equation (7). Furthermore, the system input angle at the altitude angle is obtained from the declination angle equation (8). The test is carried out from 08.00 WIB until 16.00 WIB, on January 5, 2020.Based on the test results that have been presented in figures $15,16,17$, and 18 . It can be concluded that the sensor value has an accuracy level at a pitch angle of $97.18 \%$ and an accuracy value at a roll angle of $96.4 \%$.

The current generated by solar module that follows the sun's movement is greater than the current generated by the solar module in a horizontal (static) position, as shown in Fig.19. This is due to more irradiations being captured by the solar module following the sun. More electron-hole pairs are created as the irradiation value increases, resulting in the current collected facing the sun 5 . The average short circuit current in the solar module following the sun is 3.5 A, whilst the average short circuit current in the horizontal solar module is $2.8 \mathrm{~A}$, as per the measurements' data.

The open voltage measurement value against the test time on the dual-axis solar panel system is $40.40 \mathrm{~V}$, and the average voltage value at the solar panel fixed system is $39.8 \mathrm{~V}$, as shown in Fig.20. The dual-axis solar panel system has a greater voltage output than the solar panel fixed system, as shown in the comparison graph of voltage results output. This is because the solar module always aligns the panels perpendicular to the sun, resulting in better outcomes than solar panels with a fixed arrangement.

Figure 21 shows that the power output of a fixed PV is lower than that of a dual-axis tracking PV. However, based on calculations from Fig.21, the latter system has an increased power output of $20.2 \%$ compared to the former $\left(0^{\circ}\right.$ axis position $)$.

The Power produced by the dual-axis panel has a better improvement in the morning and the afternoon time. However, it is not significantly improved in the midday time. The fixed panel is optimized for converting the solar energy in the midtime. The condition that causes the energy produced at midtime is not much different from the panel with a dual-axis tracker.

\section{CONCLUSION}

Based on the results, it can be concluded that sensor value has an accuracy level of $97.18 \%$ for pitch angle and $96.4 \%$ for roll angle. When an additional system response controller that can reach the set point faster is 
used, the time needed to reach a stable state is faster and produce a reduction of oscillation in the system response. The result of this study shows that a dualaxis PV increased output by $20.2 \%$ compared to a fixed $\mathrm{PV}\left(0^{\circ}\right.$ axis position $)$. This is because, in comparison to a fixed PV, dual-axis PV adjusts the solar panel perpendicular to the sun's position to optimize electrical conversion.

\section{REFERENCES}

[1] NA, H., Potency of solar energy applications in Indonesia. International Journal of Renewable Energy Development, 2012. 1(2): p. 33-38

[2] Aprillia, B. S., Keswara, I. M. H., Raharjo, J., Ramdhani, M., Adam, K. B., \& Suhartono, E. (2020, December). Standalone Photovoltaic System Cost Optimization for Matantimali Village Central Sulawesi. In IOP Conference Series: Materials Science and Engineering (Vol. 982, No. 1, p. 012023). IOP Publishing.

[3] Aprillia, B.S. and M.A.F. Rigoursyah, Design On-Grid Solar Power System for 450 VA Conventional Housing using HOMER Software. 2020.

[4] Sun, H., Wang, H., \& Qi, W. (2018). Automatic power decoupling controller of dependent power decoupling circuit for enhanced transient performance. IEEE Transactions on Industrial Electronics, 66(3), 18201831.

[5] Masih, A., \& Odinaev, I. (2019, April). Performance Comparison of Dual Axis Solar Tracker with Static Solar System in Ural Region of Russia. In 2019 Ural Symposium on Biomedical Engineering, Radioelectronics and Information Technology (USBEREIT) (pp. 375-378). IEEE.

[6] Mitrofanov, S. V., Baykasenov, D. K., \& Suleev, M. A. (2018, October). Simulation model of autonomous solar power plant with dual-axis solar tracker. In 2018 International Ural Conference on Green Energy (UralCon) (pp. 90-96). IEEE.

[7] Fuentes, M., Vivar, M., Burgos, J. M., Aguilera, J., \& Vacas, J. A. (2014). Design of an accurate, low-cost autonomous data logger for PV system monitoring using Arduino ${ }^{\mathrm{TM}}$ that complies with IEC standards. Solar Energy materials and solar cells, 130, 529-543.

[8] Sawant, A., Bondre, D., Joshi, A., Tambavekar, P., \& Deshmukh, A. (2018, August). Design and analysis of automated dual axis solar tracker based on light sensors. In 2018 2nd International Conference on I-SMAC (IoT in Social, Mobile, Analytics and Cloud) (I-SMAC) ISMAC (IoT in Social, Mobile, Analytics and Cloud)(ISMAC), 2018 2nd International Conference on (pp. 454-459). IEEE.

[9] Tina, G.M., F. Arcidiacono, and A. Gagliano, Intelligent sun-tracking system based on multiple photodiode sensors for maximisation of photovoltaic energy production. Mathematics and Computers in Simulation, 2013. 91: p. 16-28.
[10] [11] de Sá Campos, M. H., \& Tiba, C. (2021). npTrack: A n-Position Single Axis Solar Tracker Model for Optimized Energy Collection. Energies, 14(4), 925.

[11] Abdallah, S., \& Nijmeh, S. (2004). Two axes sun tracking system with PLC control. Energy conversion and management, 45(11-12), 1931-1939.

[12] Ahmad, S., S. Shafie, and M.Z.A. Ab Kadir, Power feasibility of a low power consumption solar tracker. Procedia Environmental Sciences, 2013. 17: p. 494-502.

[13] Batayneh, W., A. Owais, and M. Nairoukh, An intelligent fuzzy based tracking controller for a dualaxis solar PV system. Automation in Construction, 2013. 29: p. 100-106.

[14] Seme, S., Štumberger, B., Hadžiselimović, M., \& Sredenšek, K. (2020). Solar photovoltaic tracking systems for electricity generation: A review. Energies, 13(16), 4224.

[15] Taheem, A., Sachdeva, A., \& Sharma, V. S. (2019). Solar Tracker: A Review.

[16] Lukman, F. S., Hasibuan, A., Setiawan, A., \& Daud, M. (2020, September). Performance Of 25 KWP Rooftop Solar PV At Misbahul Ulum Building, Lhokseumawe City. In 2020 4th International Conference on Electrical, Telecommunication and Computer Engineering (ELTICOM) (pp. 81-86). IEEE.

[17] Xin-jiang, L. I. U., Yong, Z. H. E. N. G., \& Chong-hui, L. I. (2020). Precise Determination of Astronomical Azimuth by the Hour Angle Method of Multiple Meridian Stars. Chinese Astronomy and Astrophysics, 44(4), 536-548.

[18] Yang, D. (2016). Solar radiation on inclined surfaces: Corrections and benchmarks. Solar Energy, 136, 288302.

[19] Othman, A. B., Belkilani, K., \& Besbes, M. (2018). Global solar radiation on tilted surfaces in Tunisia: Measurement, estimation and gained energy assessments. Energy Reports, 4, 101-109.

[20] Zadeh, L.A., Fuzzy sets. Information and control, 1965. 8(3): p. 338-353.

[21] King, P.J. and E.H. Mamdani, The application of fuzzy control systems to industrial processes. Automatica, 1977. 13(3): p. 235-242.

[22] Hagras, H.A., A hierarchical type-2 fuzzy logic control architecture for autonomous mobile robots. IEEE Transactions on Fuzzy systems, 2004. 12(4): p. 524539.

[23] Tan, D.W.W.W., A simplified type-2 fuzzy logic controller for real-time control. ISA transactions, 2006. 45(4): p. 503-516. 